\title{
Designing for sustainability: Breakthrough or suboptimisation?
}

\author{
Daniel Pargman \\ School of Computer Science and \\ Communication \\ Centre for Sustainable Communications \\ KTH Royal Institute of Technology \\ Stockholm, Sweden \\ pargman@kth.se
}

\author{
Edvard Ahlsén \\ School of Computer Science and \\ Communication \\ KTH Royal Institute of Technology \\ Stockholm, Sweden \\ edvarda@kth.se
}

\author{
Cecilia Engelbert \\ School of Computer Science and \\ Communication \\ KTH Royal Institute of Technology \\ Stockholm, Sweden \\ ceen@kth.se
}

\begin{abstract}
Technological developments in screen technologies pitches the thinner, brighter and energy-stingy OLED screen as a possible replacement for today's television, computer and smartphone LCD screens. An OLED screen does not consume any energy at all when it displays the color black, but the potentially large energy savings can unfortunately evaporate and instead turn to losses when white is displayed. There is thus a mismatch between on the one hand the energy profiles of $O L E D$ screens and on the other hand user habits and current webpage design practices. This example thus raises important questions about system boundaries and about how to evaluate sustainable (or "sustainable") technologies.
\end{abstract}

We conducted a pilot study of user acceptance of alternative, OLED-adapted color schemes for webpages. We briefly discuss the results of the study, but primarily use it as a starting point for discussing the underlying questions of where, or indeed even if it makes sense to work towards realising the OLED screens' potential for energy savings. Moving from LED to OLED screens is not only a matter of choosing between competing screen technologies, but would rather have implications for hardware and software design as well as for the practices of web designers, end users and content providers.

Index Terms - Sustainability, suboptimisation, OLED, energy consumption, mobile devices, agency, systems thinking, Sustainable HCI

\section{INTRODUCTION}

We all want a more sustainable society, but what does that mean and how do we move in that direction? Do we solve one small problem at a time or should we instead strive for a holistic perspective that looks at the larger picture? David MacKay (Chief Scientific Adviser to the UK Department of Energy and Climate Change between 2009-2014) definitely thinks we should concentrate on the latter and he ridicules the ethos of "every little bit helps" [1, p.3]. MacKay counters in the introduction of his book [1] by stating that "if everyone does a little, we'll achieve only a little". If we are to cut carbon emissions significantly (70-85\% by 2050 according to $[2,3])$, we need to think in terms of phasing out fossil fuels entirely. Such a perspective implies that we should spend our time, our energies and our thoughts on those endeavors that support that ambitious goal and that anything less is futile or in the worst case perhaps even an exercise in self-deception [4]. Such a "hard-line" perspective on the other hand clashes with many practical concerns in R\&D. Researchers are for example incentivised to concentrate on the next small problem and to maximise the number of publications at conferences and in prestigious journals. The emphasis in the field of HumanComputer Interaction (HCI) is for example firmly on running projects and (short) experiments that can result in a publication at next year's conference. Some of the research presented at that conferences will concern issues that pertains to computing and sustainability, but the size of the problems, the duration of the studies reported and the pressures on publishing results at a fast pace will will tend to exert pressure also on these studies.

So how do we know if the research we are conducting actually supports a shift to a sustainable society, or, if our research instead for the most part is an exercise in suboptimisation - of solving small problems that don't make a difference in the larger whole? To answer that question, we need to initiate more discussions about what exactly we mean by "sustainability", as well as about system boundaries and suitable criteria for evaluating the computer systems we design. In this article we use a study as a concrete example and a starting point for discussing these questions. Questions regarding systems thinking and holistic perspectives have previously been been presented and the ICT for Sustainability conference, for example in $[5,6]$.

There is much hope that a new screen technology, OLED, could lead to significant energy savings compared to current (LED) screens. Since screen technologies have spread rapidly and occupy new niches in our everyday lives, we find that they are an interesting case to study. Beyond more traditional screens in the form of TVs and PCs, we are nowadays surrounded by a variety of screens that are intimate (smartphones), portable (tablets) homely (smart homes, intelligent fridges), ubiquitous (electronic shelf lables) and public (large public displays). 
The hoped-for energy savings of OLED screens in comparison to LED screens are primarily actualized when the color black is displayed on a screen, and OLED screens would therefore necessitate the need for black rather than white as the default background color on the webpages we display on our screens. Based on this, we conducted an experiment that explored user acceptance of alternative, OLED-adapted color schemes for webpages. We start this paper by describing OLED technologies, the experiment we conducted and the results of that experiment. We then use the experiment as a starting point for discussing larger issues pertaining to sustainability, to system boundaries and to the criteria we use to evaluate the systems we design and the effects of those systems.

\section{ON OLED SCREENS}

In order to decrease our $\mathrm{CO} 2$ emissions, we need to reduce our use of energy, including electricity. When using a personal computational device (smartphone, tablet, laptop etc.), the screen is one of the most energy-consuming parts of the system. On paper [7] found that the screen together with the CPU were the most energy-consuming parts of a laptop and another paper [8] found that the screen together with the GSM subsystem were the most energy-consuming parts of a smartphone. Meeting the challenge of decreasing the energy consumption of computational devices, it therefore makes sense to examine how a shift away from today's (comparatively) energy-hungry LCD screens to more energystingy screens technologies could help save electricity.

One promising technology for reducing the energy consumption of television, computer, tablet and smartphone screens is "organic LED", or, organic light-emitting diodes (OLED) [9]. The main difference between OLED and LCD screens is that OLED screens do not require any backlight since the pixels themselves are luminescent (emit light) [10]. The energy required to produce an image on an OLED screen therefore depends on the aggregate sum of the energy that is required to make all the individuals pixels emit light with the right luminosity ("brightness") and hue ("color").

An image with a lower overall luminosity will consume less power on an OLED screen and this makes OLED screens different from, and better than LCD screens. For LCD screens, an image with a lower luminosity will still require the full use of the screen's (energy-hungry) backlight and the LCD screen will then block parts of that light in order to produce the desired image. In terms of color, each pixel in an OLED screen is made up of three colour components: red, green and blue. The blue color component is usually more power-demanding than the red and green color component. An image with a blue background therefore consumes more energy than an image with either a green or a red background. Furthermore, all the aforementioned colors and backgrounds (blue, green and red) will always consume less energy than a screen with a white background, since a pixel showing pure white uses all three colour components at full intensity. A black background instead uses no color components and will therefore not consume any energy at all.
Compared to the LCD screens that dominate the market today, OLED screens have the potential to contribute to significant energy savings. Exactly how significant is difficult to say with any certainty as the actual energy savings depend on various factors, including the moment-to-moment practical use of the screen in question, e.g. whether it displays text, video, black-and-white or color images etc. In a paper from 2004, the authors conducted experiments and estimated that the energy savings could fall somewhere between $22 \%$ and $88 \%$ on a handheld device with an OLED screen compared to an LCD screen [11]. The wide range depended on the particular task performed (e.g. taking notes, reading a book, replying to an email etc.). Others have shown that it is possible to realize energy savings of upwards to $72 \%$ with today's technologies by modifying the colors displayed on an OLED smartphone screen [12]. While OLED screens in comparison to LCD screens have certain advantages (costs, response time etc.) as well as disadvantages (lifespan, sensitivity to water etc.), we are here only interested in the specific characteristics of OLED screens that pertain to their energy consumption vis-a-vis LCD screens.

Calculations of potential (future) energy savings can however differ significantly since they among other things depend on difficult-to-predict factors such as users' individual and/or social habits (e.g. the difference between energy savings of between 22 to $88 \%$ as reported above). Another large uncertainty is the fact that OLED represents a technology that is still under development and where there exist several different types of OLEDs, each with their own specific characteristics and applications; PMOLED, AMOLED, Transparent, Top Emitting, Bottom Emitting, Foldable and White OLED [9]. Future technological breakthroughs in OLED basic and applied research could mean that further energy savings could be realized in comparison with what current technologies allow. The full realization of all (potential) OLED energy savings however build on the premise that websites will be redesigned, since today's default standard white background usually consumes more energy on OLED screens than on a LCD screens.

While basic and applied research on OLED screens provide the foundation for a potential to save energy, several other "levels" beyond the hardware need to come together in order to realize the full energy saving potential of OLED screens. These "levels" span 1) software to harness and make use of the hardware, 2) practices of content providers and web designers as well as 3) the behavior of the end users. Who should, and where does it make the most sense to work towards realizing these (potential) energy savings? Based on these questions, we conducted an experiment about user acceptance of alternative, OLED-adapted color schemes for webpages. We are in particular interested in users' reactions to webpages that are redesigned so as to take advantage of the energy-saving capacities of OLED screens?

\section{PILOT STUDY}

To realize the full potential energy savings of OLED technologies, end users would have to switch to different, more 
"OLED-compliant" color schemes with other background colors than white. This is obviously a challenge since white "unfortunately" is the most popular background colors for webpages today. To test users' acceptance of alternative, more "OLED-compliant" color schemes, we created three prototypes with alternative color schemes (see figure $1 \mathrm{~b}-1 \mathrm{~d}$ below).
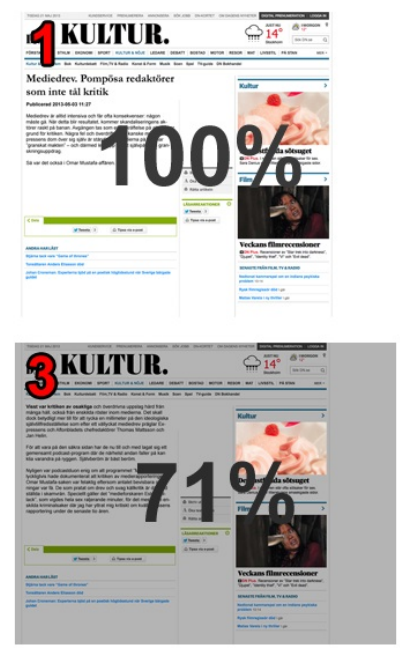

Fig. 1. Display of the original while webpage (figure 1a), the light green prototype 1 (figure $1 \mathrm{~b}$ ), the light grey prototype 2 (figure $1 \mathrm{c}$ ) and the inverted prototype 3 (figure 1d).

Figure $1 \mathrm{a}$ is the original, unaltered and non-OLEDcompliant webpage with a white background color. Since a common energy-profile of currently OLED displays has green pixels use less energy than both red and blue pixels, figure $1 \mathrm{~b}$ displays a webpage where the white background has been replaced by a light green color. According to our calculations, we estimate that this webpage, if displayed on an OLED screen, would use $85 \%$ of the energy of the white webpage (figure 1a). Figure 1c displays the homepage with the same color scheme as 1a, but with decreased luminance ("brightness"). The luminance has been decreased from 1 (white) to 0.73 (light gray) and the energy consumption is, according to our calculations, $71 \%$ of the white (figure 1a) homepage. In figure $1 \mathrm{~d}$, the colors have been inverted so as to show white text on a black background. This is the most energy-stingy color scheme and it was estimated to use as little as $11 \%$ of the energy of the white webpage.

While most studies of energy consumption of OLED screens have focused on the hardware and/or software, our study [13] instead focused on the interface between the hardware/software and the human uses and the human users of OLED screens, including implications for content providers and web designers

Our informants $(n=46)$ were recruited from two different groups, namely students $(n=39)$ and news journalists $(n=7)$. They were asked to read a short newspaper article that we garnered from the online edition of Sweden's largest morning newspaper, Dagens Nyheter. We divided the text into four parts and informants started reading the story on the original, unaltered white webpage (figure 1a) only to then continue to read the story on the various altered webpages (figure 1b-1d). Informants had to answer questions about the experience of reading text on the specific webpage in question before progressing to the next part of the news story and the next webpage.

Informants were at this point not aware of the purpose of the study. If pressed for an answer, we believe they would have guessed that they were partaking in a study of alternative webpage design rather than in a study of the potential energy savings of OLED screens. After having finished reading the story, informants were given some basic information (150 words) about OLED screens and a short survey. It was thus only after answering questions about the convenience (or not) of reading text with the four different color schemes that informants became aware of the fact that these different colorschemes for webpages can consume (sometimes radically) different amounts of energy. Taking into account that the justconveyed information might sway or change informants' opinions, they got a final opportunity to answer how often/if they would consider using each webpage as an alternative to the original (figure 1a), white webpage.

\section{RESULTS}

Of the 46 respondens, 39 were students (19-32 years old) and 7 were news journalists (24-62 years old). Students were chosen for practical reasons (e.g. access) and journalists were chosen due to the focus on online news (e.g. relevance). All respondents had used a computer the proceeding day and $65 \%$ had spent 4 hours or more in front of a computer. Almost $90 \%$ of the respondents read news regularly on the Internet and $50 \%$ read news online once or several times each day.

All three prototypes received mixed comments with the third prototype (figure 1d) receiving the most positive (least negative) reception, but only by a relatively small margin. Opinions were divided, i.e. someone would invariably like a prototype ("comfortable for the eyes") that someone else disliked ("strenuous", "ugly"). Some comments went beyond comfort and discussed habits ("comfortable, but unaccustomed") or aesthetics ("easy to read, but not that beautiful"). Others again had opinions about the connotations of different designs ("not very Dagens Nyheter") as well as genre conventions ("felt unserious").

After the informants had received basic information about OLED screens' potential energy-saving characteristics, they were queried in regards to whether they would use any of the three prototypes as alternatives to the original, unaltered webpage (figure 1a). For each prototype, they could choose between "always", "often", "now and then", "seldom" and "never". As imagined, respondents were at this point particularly receptive to switching to prototype 3 (figure 1d) due to the large energy savings potential. Almost half the informants $(48 \%)$ stated that they would use prototype 3 "often" or "always" if that alternative was available (versus $20 \%$ and $22 \%$ for prototypes 1 and 2 ). It should however be noted that while the informants clearly understood that OLED screens had a high energy-saving potential, only a minority of the informants specified environmental concerns - rather than 
battery life - as a motivation for using alternative energy-saving webpage color schemes:

"I would obviously imagine myself web surfing in an environmentally friendly way and accept a certain degree of inconvenience for the good of the environment" (journalist, 61 years old).

"If I had an OLED screen in my mobile phone or in other devices that use batteries, then I would definitely use the most energy saving variant" (student, 22 years old).

"I would probably think more about the fact that I would get longer battery life than [I would think of] actually using less energy" (student, 28 years old).

A concise summary would state that to most of our informants, saving batteries is more important than "saving the world". Other informants emphasized other factors besides batteries and energy savings as being equally or more important for influencing their behavior; laziness, eyestrain, headaches, the time necessary to load webpages and quality of editorial content. Finally, one person sensibly pointed out that it is difficult to make a decision without knowing a more about the whole issue of the energy consumption of screens:

"I would first of all be curious as to how much energy you save in actual numbers, or get a comparison with something else (flying to Thailand, eating meat, printing an e-mail) - only then would I really be able to decide to what extent I'd be willing to change my browsing habits. But I can definitely see me using the last [figure 1d prototype], if it brings reasonably good energy-savings" (editor in chief, 24 years old).

It should be noted that the three prototypes (figure 1b-1d) do not necessarily give a totally fair understanding of what a redesigned webpage for a news site would actually look like. Changing the background color would surely have cascading implications for webpage design both in terms of readability and aesthetics. It is thus difficult to ascertain what further changes would be necessitated by a change of background color (for example in terms of choices of fonts, images, these images' color schemes etc.).

Based on the results of the study, we can at this point conclude that opinions in general are mixed but that almost half of our informants stated that they would use the energy-stingy lback webpage (figure 1d) often or always and that most informants were willing to switch not primarily because of the energy savings per se but rather due to reasons of battery life (convenience). With OLED energy savings of upwards to $90 \%$ compared to LED screens, it would seem that a switch from the latter to the former would seem like a very good idea indeed. The purpose of this paper is however to discuss system boundaries and to problematize these results. We will do so in two steps; first by discussing what a switch to OLED screens would mean in a larger context where the screen is only one factor in an ecosystem of hardware, software, content, services and end-user behaviors. Second, we will further widen the systems boundaries and discuss a switch to OLED screens in relation to the need to replace hardware and taking the embodied energy of the devices in question into account. Returning to the question posed in the introduction of the paper, we can then ask ourselves if energy savings of upwards to $90 \%$ for screens represent a breakthrough or if we are instead fooling ourselves by optimising a small and relatively inconsequential part of a larger system.

\section{ON GREEN IN ICT VS GREEN BY ICT}

Hilty et. al. [14] specifies and discusses the difference between "Green in ICT" and "Green by ICT". Green in ICT refers to "the resource consumption and the sustainability impact of the ICT sector itself" while Green by ICT (sometimes called "Green through ICT") refers to the potential of ICT to decrease the environmental impact of other (nonICT) sectors of the economy.

Green in ICT does not only encompasses the direct energy consumption (and $\mathrm{CO} 2$ emissions) of the ICT sector $[15,16]$, but also considers other aspects such as miniaturization, integration, hardware churn/obsolescence $[17,18]$, resource use $[19,20]$ as well as the end-of-life treatment (e.g. formal or informal recycling or disposal of e-waste, e.g. see [21]. Further distinctions can also be made, for example between greening in hardware versus greening in software [22]. Greening in hardware can refer to improved manufacturing techniques that makes use of less materials and less energy in production processes or that results in more energy-efficient hardware. Greening in software can refer to writing better (faster, more energy-stingy) software rather than producing bloated, sloppily written code as well as to designing software that reduces the energy consumption of hardware [23]. Penzenstadler et. al. [24] argue that sustainability should be considered a nonfunctional requirement in the software engineering process, similar to safety and security.

Green by ICT instead regards ICT as an enabling technology that can improve or substitute energy-consuming process in other sectors, for example through better management of the heating and cooling of buildings, or by increasing the efficiency of, or indeed totally substituting physical transports through intelligent applications of ICT [14].

The matter of interest here - OLED screens - spans these distinctions. It is a matter of hardware, software, end-user habits and of content production and web design. In this particular case, and since OLED screen are only one factor in an ecosystem of hardware, software, content, services and enduser behaviors, it becomes difficult to make use of the distinction between Green in vs Green by ICT. Are OLED screens primarily a matter that relates to "the ICT sector itself", or, does that fact that newspapers and other websites need to redesign their web pages imply that this is an example of ICT decreasing the environmental impact of the media sector? We will develop this argument below.

\section{WHERE IN THE WORLD IS ENERGY ACTUALLY SAVED?}

OLED technologies primarily represent progress in hardware design (and the underlying physics, material sciences etc.). It would perhaps seem logical that the potential energy savings would best be "captured" in the hardware itself, by building hardware that is more energy-efficient than current alternative technologies (LCD etc.). But if the full potential of OLED screens can not be realized as long as web page colour 
schemes stay the same, there is obviously more at play here than just replacing one hardware technology with another. As has already been mentioned, the end result of a shift to OLED screens without corresponding shifts elsewhere could be that potential savings remain unrealized (e.g. "squandered"), or that the combination of OLED screens together with today's white web pages would in fact be less rather than more energy efficient in comparison to current technologies.

One suggestion for realising the potential of OLED screens is to utilize software that automatically controls and harnesses the energy-saving potential of OLED hardware, for example by automatically transforming web page color schemes and optimized them for energy effectiveness in general and for OLED screens in particular. That is for example the idea behind the Chameleon web browser [12]:

"Chameleon [is] a color adaptive web browser that renders web pages with power-optimized color schemes [...] Chameleon is able to reduce average system power consumption for web browsing by $41 \%$ and reduce display power consumption by $64 \%$ without introducing any noticeable delay" (ibid.)

Software that automatically controls and harnesses the potential of the hardware and that automatically translates web page color schemes might however provide a less-than-optimal experience for the end user, even if the task is performed "under user-supplied constraints" (ibid.). Such a solution would furthermore tend to make content providers and web designers nervous as they obviously dislike the idea of losing control and having their carefully crafted and aesthetically pleasing websites "hijacked" and automatically transformed by aesthetically illiterate energy-saving software. This implies that there are additional stakeholders that might indeed have strong opinions about exactly how web pages should be displayed on a screen. Content provides (e.g. online newspapers or other service providers) want a degree of control over how their content is displayed on the screen and over the user experience. The individual end user might also have opinions of her own. As was reported above, different users might furthermore have different preferences about how the same web page should be displayed.

This all makes it difficult to pinpoint exactly where and by whom the energy-saving potential of OLED screens should be realised. Are these questions primarily a matter best left to hardware engineers, to software developers, to content providers and web designers or to end users (or to some combination of these stakeholders)? While many questions remain, we can at least know for sure that harvesting the potential energy savings of OLED screens is a complicated matter that is much harder than just designing new-andimproved hardware. While, as stated above, it is technically true that "OLED screens have the potential to contribute to significant energy savings", these savings seem more elusive than before as the system boundaries are stretched beyond being only a matter of hardware to encompass an ecosystem of hardware, software, content, services and end-user behaviors. This "complication" in itself puts the hoped-for savings at risk.

\section{A HOLISTIC PERSPECTIVE}

"Sustainability requires an understanding all of a system's inputs and outputs, and its systemic effects [...] Yet, it is too often the case that computing systems that purport to be "green" or "sustainable" selectively draw a tight boundary around the implemented system in question and then proceed to squint hard in order to ignore important but "problematic", input and/or output flows. [...] by widening the system boundaries and by adopting a more holistic perspective, radically different solutions might become conceivable or even apparent" [4].

In an effort to discuss system boundaries and how to evaluate sustainable technologies, we now return to the fundamental questions that were posed in the introduction of this paper and indeed in the very title of the paper. Do OLED screen technologies represent a breakthrough or rather a case of suboptimisation - of solving a small problem that doesn't make a difference in the larger whole?

We here draw parallels to the lively debate in Sustainable HCI [Human-Computer Interaction] about what constitutes suitable objects for HCI research that focuses on sustainability [25, 26, 27, 28]. DiSalvo et. al. [25] for example discuss various tensions within Sustainable HCI and those most relevant to the issues being discussed in this paper are:

- Focus on designing solutions for individual consumers and their choices vs solutions for groups, multiple stakeholders and all the way up to solutions for nation-states.

- Focus on technology as an adequate solution in itself ("techno-fix") vs technology as part of broader efforts (policy reform, business practices, consumer education etc.).

- Focus on supporting current lifestyles ("for example by supporting existing activities while reducing their resource usage") vs the need for more fundamental cultural change.

- "HCI as usual vs. HCI must be rethought" - which in this context can be translated to a tension between R\&D as usual (working with existing methods and orientations) vs R\&D must be rethought (because it contributes to unsustainability, for example by supporting wasteful cycles of rapid obsolescence).

The case of OLED screens can to some extent be compared to the object of various eco-feedback studies [29] where the hoped-for goal of various interventions is to decrease household electricity use (or water use etc.) by a certain fraction. These studies have on the other hand been criticised because while they might increase the efficiency of existing practices (sometimes marginally), the do not at all work towards the adoption of less resource-intensive practices [26, 30, 31].

What often is not at all considered - the elephant in the room - is that the energy savings of an intervention ought to be related to the costs of that same intervention. The energy that a digital device uses is only a part of the total energy consumption if we add also the energy necessary to run the underlying infrastructure (e.g. the Internet) that makes the 
device useful. In addition to the costs of charging a device, we should thus also add the costs of running data centers and the computer networks that conveys the data traffic $[32,33,34]$. In a best-case scenario, OLED screens could reduce the energy consumption of upwards to $90 \%$ compared to LCD screens. The devices themselves would however still generate a carbon footprint even if the screens (which are, after all, only one part of the device) consumed no electricity at all!

The energy costs and the carbon footprint of digital technologies is however not just a matter of the use phase, but rather spans the whole chain from extraction of minerals and other resources to the design, manufacturing, distribution, installation, servicing and, eventually, the disposal of the devices [35].

"The vast majority of research motivated to help reduce $\mathrm{CO} 2$ emissions deals with the consumption stage of the IT product life-cycle - i.e. reducing the amount of energy consumed during the use of technology. By comparison, embodied carbon of IT (the production stage) is largely omitted from the problem domain" [27].

A physical device is thus not born through the technological equivalent of immaculate conception. It is instead born with a heavy backpack in terms of embodied energy - emergy - that stems from the energy that is used during the process of manufacturing the device. The embodied energy for a smartphone is many times higher [16] than the total amount of energy used during the typically 18-24 months [36] that a smartphone is used (in developed countries) before it is replaced (see further calculations below).

"Although seldom specified, there is also some time span after which the devices must be replaced (perhaps as short as a few years). We should thus also consider the embodied energy of the larger [...] system and if it is greater than or equal to the savings the system was supposed to produce, then it is most certainly not beneficial" [4].

Another researcher authoritatively states that "As a rule of thumb, the length of the useful life of most ICT devices is more important than their power consumption during use" [37]. It would therefore be problematic if the potential energy savings of switching to an OLED screen would encourage people to replace their telephones at an even faster pace. Easterbrook [5] argues that ICT, instead of for the most part doing good for the environment, usually is "part of the drive to ever growing consumption, as the combined effect of Moore's law and built in obsolenscence shorten produce lifeftimes for hardware, while the desire for greater connectivity accelerates demand for new gadgets."

So where does that leave us? We have earlier in the paper stated that "OLED screens have the potential to contribute to significant energy savings", but we have also later stated that "these savings seem more elusive [...] as the system boundaries are stretched beyond being only a matter of hardware [...] to encompass an ecosystem of hardware, software, content, services and end-user behaviors". Here we finally arrive at the conclusion that while the savings of OLED screens are significant in relation to the energy consumption of LCD screens, they are not very significant in the larger whole and especially not when pitted against the challenge of cutting carbon emissions significantly (by 70-85\%) by 2050 .

The scope of the chosen solutions should naturally be commensurable with the scope of problems and accepting a radical curtailing of carbon emissions as an overarching goal, the goal for research pertaining to sustainability should then be to find ways to design for a "3-tonne lifestyle" [3], i.e per capita $\mathrm{CO} 2$ emissions that are significantly below today's global average of around 5 tonnes of $\mathrm{CO} 2$ emissions per capita [38] (Olivier et. al. 2015). Adopting that high-level goal has further implications and raises many subsequent questions, for example "How can we enable less carbon-intensive social practices?" [27].

"Turning off lights, unplugging unused appliances, and conserving water are all important. But focusing only on simple acts sidesteps more difficult lifestyle choices that may in fact be necessary to work toward a more sustainable society" [26].

Based on this perspective, we can unequivocally conclude that a switch from one screen technology to another would have a truly insignificant impact in the larger whole. This conclusion is supported by juxtapositioning MacKay [1], who states that the average European consumes $125 \mathrm{kWh}$ of energy per day (ibid., p.104), with the trivially small energy requirements of a modern smartphone. Fully charging an iPhone 5 or a Samsung Galaxy SIII consumes 9.5 Wh and 12.3 Wh respectively [39]. Doing so once per day for a year adds up to $3.5 \mathrm{kWh}$ and $4.5 \mathrm{kWh}$ respectively. These figures are also comparable to the corresponding figures of the more recent iPhone 6 and iPhone 6 Plus [40], despite the latter having significantly larger screens. Do note that the daily energy consumption of the average European is quivalent to charging such a phone from 0 to $100 \%$ once per day for 40 years or so!

As mentioned above, the possible energy savings are also dwarfed by the massive amounts of energy that is used in the process of manufacturing the smartphone. It has been estimated that the embodied energy of a smartphone is in the order of 1 gigajoule (GJ), or, $278 \mathrm{kWh}$ [16]. That means that the energy that has been used to manufacture the phone corresponds to charging the phone once per day for upwards to 70 years!

Does that mean that R\&D in OLED screen technologies actually should be abandoned? To answer that question is beyond the scope of this paper, but we can unequivocally establish that research on alternative screen technologies (i.e. OLED) can not and should not be motivated or justified in terms of sustainability. It is easier and more sensible to motivate and justify such research in terms of longer battery life and increased convenience for end users. This is also in line with what was of most interest to our informants as an impetus for behavior change.

\section{CONCLUSION}

We have concluded that while OLED screens represent a new technology with interesting implications, it is difficult (verging on impossible) to justify a switch from today's LED screens to OLED screens by referring to "sustainability". This is true not the least because the potential savings are small and 
because there are several pitfalls that actually threaten to make such a switch worse from a sustainability point of view. As was reported above, one of the informants shrewdly commented that:

"I would first of all be curious as to how much energy you save in actual numbers, or get a comparison with something else (flying to Thailand, eating meat, printing an e-mail) - only then would I really be able to decide to what extent I'd be willing to change my browsing habits. But I can definitely see me using the last [black prototype], if it brings reasonably good energy-savings".

Switching to OLED screens and taking on the added costs of possible inconvenience to the end users, as well as the costs to other stakeholders (content providers, web designers) is certainly not the best way to decrease an individual's per capita carbon emissions. While the cost of printing a single e-mail is insignificant, one less trip around the world or a decrease of the consumption of meat would instead have a significantly larger impact on the individual's carbon emissions.

It would at this point be easy to end the paper with a call to arms for ordinary people to be more "rational" and alter their habits and lifestyles in such ways so as to make the largest possible impact in terms of their own individual carbon emissions. Christensson et. al. [41] note how "irrational" most people are when it comes to reasoning about the environmental costs of their lifestyles:

"Usually, only some selected areas of consumption and consumer behaviour are thematized in an environmental perspective, whereas extensive parts of environmentally problematic consumption are neglected. [...] Instead of assessing their overall behaviour in an environmental perspective, consumers consider only a small subset [...] of actions environmentally relevant such as, for instance, recycling, buying organic vegetables, and using energy-saving bulbs."

Blaming solely the individual is however problematic. As we have shown, this particular problem is considerable more complex and many important aspects are far beyond what the indivual end users can do or what they have a say about. Dourish [42] notes that:

"When environmental action is framed in terms of individual acts of consumption in an unfettered market, questions of state regulation and of corporate responsibility are written out of the picture. [...] The rhetoric of individual moral choice exemplifies a broader cultural discourse in which questions of social justice and responsibility are transformed into matters of individual action."

Switching to a new smartphone with an OLED screen runs the risk of becoming a compartmentalised action that allows us as individual to feel as if we are "doing something for the environment" while we simultaneously avoid assessing the true environmental impact of our lifestyles. But finding ways forward in the face of environmental and other challenges must also be a matter beyond the individual's decsions to hold on to their "old" cell phones for yet another year, and instead involve also other societal actors and other societal dimensions (institutional, political, cultural, legal, economic etc.).
While the choice of which type of screen to use might not be very significant in the larger whole [1], this particular issue does point to the importance of holistic perspectives when it comes to sustainability as well as the need to complement individual actions with state and corporate actions and responsibilities.

We end the paper by encouraging others to adopt a holistic perspective and take up the theme of exploring systems boundaries and systems thinking when analysing ICT systems. We have here focused on a particulary technology (OLED screens) and particular devices (mainly smartphones but also PCs). We have above asked if "OLED screen technologies represent a breakthrough or rather a case of suboptimisation of solving a small problem that doesn't make a difference in the larger whole?". While we have looked at a particular system, the same question - breakthrough or suboptimisation? - could be directed at other specific systems and at other levels; e.g. of the smart home, smart grids, the Tesla Powerwall, smart transportation (self-driving cars etc.), smart sustainable cities and at the topmost level of the global information infrastructure.

\section{ACKNOWLEDGEMENTS}

We would like to thank an anonymous ICT4S reviewer for the insightful comments and also take the opportunity to express our regets that we could not follow through on more of the excellent advice due to time constraints.

\section{REFERENCES}

[1] MacKay, D. (2008). Sustainable Energy - without the hot air. UIT Cambridge.

[2] Baer, P., \& Mastrandrea, M. (2006). High stakes: designing emissions pathways to reduce the risk of dangerous climate change. London: Institute for Public Policy Research.

[3] Berners-Lee, M. (2010). How bad are bananas. The carbon footprint of everything. London: Green Profile.

[4] Pargman, D., \& Raghavan, B. (2014). Rethinking sustainability in computing: From buzzword to non-negotiable limits. In Proceedings of the 8th Nordic Conference on Human-Computer Interaction, pp. 638-647. ACM.

[5] Easterbrook, S. (2014). From Computational Thinking to Systems Thinking. In The 2nd international conference ICT for Sustainability (ICT4S), Stockholm.

[6] Sedlacko, M., Martinuzzi, A., \& Dobernig, K. (2014). A Systems Thinking View on Cloud Computing and Energy Consumption. In The 2nd international conference ICT for Sustainability (ICT4S), Stockholm.

[7] Mahesri, A., \& Vardhan, V. (2005). Power consumption breakdown on a modern laptop. In Power-aware computer systems (pp. 165-180). Springer Berlin Heidelberg.

[8] Carroll, A., \& Heiser, G. (2010). An analysis of power consumption in a smartphone. In Proceedings of the 2010 USENIX conference on USENIX annual technical conference (pp. 21-21).

[9] Kalyani, N. T., \& Dhoble, S. J. (2012). Organic light emitting diodes: energy saving lighting technology-a review. Renewable and Sustainable Energy Reviews, 16(5), 2696-2723.

[10] Dong, M., \& Zhong, L. (2012a). Power modeling and optimization for OLED displays. Mobile Computing, IEEE Transactions on, 11(9), 1587-1599. 
[11] Harter, T., Vroegindeweij, S., Geelhoed, E., Manahan, M., \& Ranganathan, P. (2004, April). Energy-aware user interfaces: an evaluation of user acceptance. In Proceedings of the SIGCHI conference on Human factors in computing systems (pp. 199206). ACM.

[12] Dong, M., \& Zhong, L. (2012b). Chameleon: a color-adaptive web browser for mobile OLED displays. Mobile Computing, IEEE Transactions on, 11(5), 724-738.

[13] Ahlsén, Edvard and Engelbert, Cecilia (2013), "Green websites for next generation displays". Bachelor's thesis, Dept of Media Technology and Interaction Design, School of Computer Science and Communication, KTH Royal Institute of Technology, Stockholm, Sweden.

[14] Hilty, L., Lohmann, W., \& Huang, E. (2011). Sustainability and ICT - an overview of the field. POLITEIA, 27(104), 13-28.

[15] Malmodin, J., Moberg, Å., Lundén, D., Finnveden, G., \& Lövehagen, N. (2010). Greenhouse gas emissions and operational electricity use in the ICT and entertainment \& media sectors. Journal of Industrial Ecology, 14(5), 770-790.

[16] Raghavan, B., \& Ma, J. (2011). The energy and emergy of the internet. In Proceedings of the 10th ACM Workshop on Hot Topics in Networks (p. 9). ACM.

[17] Packard, V. (1960). The waste makers (Vol. 35). New York:.

[18] Remy, C., \& Huang, E. M. (2015). Addressing the obsolescence of end-user devices: Approaches from the field of sustainable HCI. In ICT Innovations for Sustainability (pp. 257-267). Springer International Publishing

[19] Wäger, P. A. (2011). Scarce metals-Applications, supply risks and need for action. Notizie di Politeia, 27(104), 57-66.

[20] Wäger, P. A., Hischier, R., \& Widmer, R. (2015). The material basis of ICT. In ICT Innovations for Sustainability (pp. 209-221). Springer International Publishing.

[21] Umair, S., Björklund, A., \& Petersen, E. E. (2015). Social impact assessment of informal recycling of electronic ICT waste in Pakistan using UNEP SETAC guidelines. Resources, Conservation and Recycling, 95, 46-57.

[22] Kazandjieva, M., Heller, B., Gnawali, O., Hofer, W., \& Kozyrakis, P. L. C. (2011). Software or hardware: The future of green enterprise computing. Computer Science Technical Report CSTR, 2.

[23] Bhattacharya, B., Gopinath, K., Rajamani, K. \& Gupta, M. (2011). "Software Bloat and Wasted Joules: Is Modularity a Hurdle to Green Software?". IEEE Computer, vol. 44, no. 9, pp. 97-101.

[24] Penzenstadler, B., Raturi, A., Richardson, D., \& Tomlinson, B. (2014). Safety, security, now sustainability: The nonfunctional requirement for the 21 st century. IEEE Software, 31(3), 40-47.

[25] DiSalvo, C., Sengers, P., \& Brynjarsdóttir, H. (2010, April). Mapping the landscape of sustainable HCI. In Proceedings of the SIGCHI Conference on Human Factors in Computing Systems (pp. 1975-1984). ACM.

[26] Brynjarsdottir, H., Håkansson, M., Pierce, J., Baumer, E., DiSalvo, C., \& Sengers, P. (2012). Sustainably unpersuaded: how persuasion narrows our vision of sustainability. In Proceedings of the SIGCHI Conference on Human Factors in Computing Systems (pp. 947-956). ACM.

[27] Knowles, B., Blair, L., Hazas, M., \& Walker, S. (2013). Exploring sustainability research in computing: where we are and where we go next. In Proceedings of the 2013 ACM international joint conference on Pervasive and ubiquitous computing (pp. 305-314). ACM.

[28] Silberman, M., Nathan, L., Knowles, B., Bendor, R., Clear, A., Håkansson, M., Dillahunt, T. \& Mankoff, J. (2014). Next steps for sustainable HCI. interactions, 21(5), 66-69.

[29] Froehlich, J., Findlater, L., \& Landay, J. (2010). The design of eco-feedback technology. In Proceedings of the SIGCHI Conference on Human Factors in Computing Systems (pp. 19992008). ACM.

[30] Strengers, Y. A. (2011). Designing eco-feedback systems for everyday life. In Proceedings of the SIGCHI Conference on Human Factors in Computing Systems (pp. 2135-2144). ACM.

[31] Strengers, Y. (2014). Smart energy in everyday life: Are you designing for resource man? Interactions, 21(4), 24-31.

[32] Bates, O., Lord, C., Knowles, B., Friday, A., Clear, A., \& Hazas, M. (2015). Exploring (un) sustainable growth of digital technologies in the home. In The 3rd international conference ICT for Sustainability (ICT4S), Copenhagen.

[33] Preist, C., Schien, D. \& Blevis, E. (2016). Understanding and Mitigating the Effects of Device and Cloud Service Design Decisions on the Environmental Footprint of Digital Infrastructure. In Proceedings of the SIGCHI Conference on Human Factors in Computing Systems. ACM.

[34] Hazas, M., Morley, J., Bates, O., \& Friday, A. (2016). Are there limits to growth in data traffic?: on time use, data generation and speed. In Proceedings of the Second Workshop on Computing within Limits. ACM.

[35] Hendrickson C, Horvath A, Joshi S, Lave L (1998) Economic input-output models for environmental life-cycle assessment. Environmental science \& technology 32(7), 184A-191A.

[36] Blass, V. D., Fuji, M., Neira, J., Favret, L., Mahdavi, S., Miller, R., \& Geyer, R. (2008). End-of-life management of cell phones in the United States. In IEEE International Symposium on Electronics and the Environment. IEEE.

[37] Hilty, L. (2008). Information technology and sustainability. Essays on the Relationship between ICT and Sustainable Development. Books on Demand GmbH, Norderstedt.

[38] Olivier, J.G.J., Janssens-Maenhout, G., Muntean, M. \& Peters, J.H.A.W. (November 2015). Trends in global CO2 emissions. JRC report 98184 / PBL report 1803. PBL Netherlands Environmental Assessment Agency. Available online at: http://edgar.jrc.ec.europa.eu/news_docs/jrc-2015-trends-inglobal-co2-emissions-2015-report-98184.pdf

[39] Fisher, B. (2012). How much does it cost to charge an iPhone 5? A thought-provokingly modest \$0.41/year. Opower blog. Available online at: https://blog.opower.com/2012/09/how-muchdoes-it-cost-to-charge-an-iphone-5-a-thought-provokinglymodest-0-41year/

[40] Fisher, B. (2014). How much does it cost to charge an iPhone 6? A remarkably slender $\$ 0.47$ per year. Opower blog. Available online at: https://blog.opower.com/2014/09/iphone-6-charging47-cents/

[41] Christensen, T. H., Godskesen, M., Gram-Hanssen, K., Quitzau, M. B., \& Røpke, I. (2007). Greening the Danes? Experience with consumption and environment policies. Journal of Consumer Policy, 30(2), 91-116.

[42] Dourish, P. (2010, August). HCI and environmental sustainability: the politics of design and the design of politics. In Proceedings of the 8th ACM Conference on Designing Interactive Systems (pp. 1-10). ACM. 